\title{
Socialised Creation Literacy Appeared during the COVID-19 Emergency: A Case Report
}

\author{
Masami Yoshida and Anuchai Theeraroungchaisri
}

\begin{abstract}
In our previous study, we proposed socialized creation competency as an advanced media information literacy. The competency involves four pillars: socialized creation, collaborative creativity, a critical eye and building affordance. The characterisation of this competency consists of all the component processes that make up social capital in ICT society. In this study, we extracted a concrete example to explain the socialised creation and to promote the sustainable development of society. The case we investigated was one in which civic IT engineers collaborated to develop program codes for a COVID-19 website. We collected and analysed related documents and communication records on Twitter. The results provided a deeper understanding of the importance of collaboration among diverse citizens, IT engineers, corporate workers and members of public sectors. Those players worked using a new style of production regarding Civic Tech and GovTech. Their activities blurred the borders of various organisations. Online services, GitHub, and other SNS were used for both creation and opinion exchanges, and emerging heterarchical communication was interrelated. The creators accepted the engagement of any citizen to vet opinions for purposes of improving the website. Records demonstrated the substantial potential for the needs of advanced MIL competency to understand civil society and collaborative creation by the public sector and citizens.
\end{abstract}

Index Terms-Civic tech, COVID-19, GovTech, media information literacy, socialised creation.

\section{INTRODUCTION}

With the diffusion of the Internet, social media has become one of the most popular services for citizens to acquire information, communicate with people over distances, and create knowledge around the world. Civic engagement is one of the most lasting and consequential effects of social media [1], [2], especially among those who use it as a tool to reach the community. Users of social media usually navigate the environment between their physical spaces along with cyberspace as they evolve together in a relationship [3]. Competences to extend out into expanding social networks, to link together with groups of various talents and to engage in online civic activities that were beyond the scope of traditional boundaries have emerged.

One of the early difficulties in exploring the popularity of social media has created a new debate over how the Internet contributes to society by allowing citizens to become

Manuscript received September 16, 2020; revised December 16, 2020.

Masami Yoshida is with the Faculty of Education, Chiba University, 1-33 Yayoi Inage Chiba 263-8522, Japan (e-mail: yoshida-m@faculty.chiba-u.jp).

Anuchai Theeraroungchaisri is with the Faculty of Pharmaceutical Sciences, Chulalongkorn University, 254 Phayathai Road, Patumwan District, Bangkok 10330, Thailand (e-mail: anuchai.t@pharm.chula.ac.th). informed, find common causes and participate in public life more often [4]. Here, citizens play a key role in the reception of information, whether to critically evaluate the content of information or to promote accountability [5]. Various anecdotal evidence shows that social media can have a prosocial effect; the United Nations Educational, Scientific and Cultural Organization (UNESCO) proposed a concrete toolkit to disseminate media and information literacy (MIL) as a composite concept, which included competencies to use social media [6].

\section{A. MIL Definition and Space}

The MIL was defined as follows: "Media and information literacy is a set of competencies that empowers citizens to access, retrieve, understand, evaluate and use, create as well as share information and media content in all formats, using various tools, in a critical, ethical and effective way, in order to participate and engage in personal, professional and societal activities" [7].

The definition reveals a need for MIL skills progression for today's citizens, including a range to contribute meaningfully to professional and societal development.

The MIL covers the following three levels of competencies [7].

1) Knowledge and understanding of media and information for democratic discourses and social participation.

2) Evaluation of media texts and information sources.

3) Production and use of media and information.

The content has an indispensable role for each level of competencies, but regarding the highest level (3), there were few cases reported to produce content by citizens.

\section{B. Advanced MIL}

Level 3 competency above specifically includes civic collaboration. While the importance of social involvement in MIL evolved, media and information literacy intercultural dialogue (MILID) expanded the MIL by introducing intercultural dialogue. It depicted ownership of the media, content and distribution channels. The MILID committed not only information that was the privately owned profit of commercial providers but also information that was a production of social capital for the community [8]. Then, the MIL in social media enhances civic engagement, a pluralistic mode of information and civic creative activities.

To develop these activities, our previous study drew on the post-level 3 competency, which included collaboration in social media and was named 'socialized creation' [9].

\section{Competency of Socialized Creation}

In our previous report, we analysed a case developed by vernacular creators of user-generated content (UGC) for 
music, and extracted concerning activities to understand collaborative creations. The case involved a variety of diverse domains of information, knowledge, creative works, as well as the engagement of various individuals and collaboration. In this arena, 'Doujin,' a group of people or friends who share an interest, activity, hobby or achievement, was detected to enhance collaborative creativity (see the second column of Table I). The emerged activities were explained by a new business strategy, 'systems of engagement' ( $\mathrm{SoE})$, that is the production systems based on connections with users. The market involves individuals in UGC development and deployment.

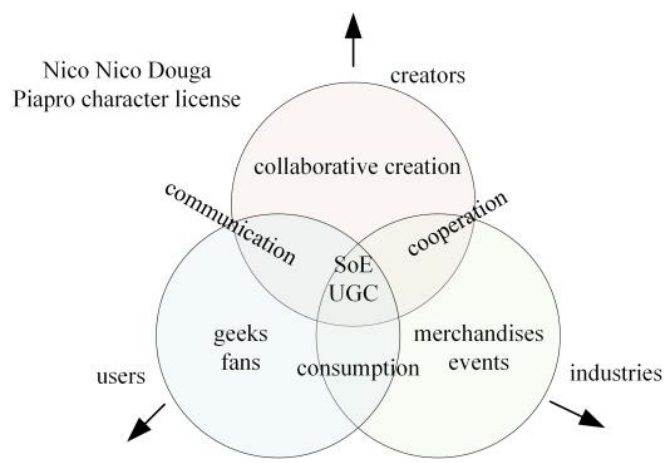

Fig. 1. An arena of social capital by UGC.

In this arena, the capital is no longer authored but resides in the social community. Fig. 1 shows the framework of an arena with the triad of elements of the social capital. In addition, requiring competency to understand the social capital, 'socialised creation' was defined as the four pillars of items (see the first column of Table I).

\section{GovTech (A Portmanteau: Government and Technology)}

The e-government has been disseminated worldwide as the application of technology to improve government efficiency or to modernize systems [10]. Continuously, the new strategy to increase efficiency in administration by digitalising work processes or bringing new tools was invented and is called 'GovTech' [11]. In GovTech, the primary beneficiaries are governments. In other words, GovTech's measures of success are efficiency gains and costs saved.

On the other hand, wide policies on open data of government and government transparency have been developed to achieve citizens' access to information and their participation in government [12], [13]. This world trend and platform for reformers was provided as a multilateral initiative of open government partnership (OGP) in a UN general assembly meeting in 2011 [14]. Then, the efficiency of GovTech is deemed as a more socialised point of view.

As a fundamental of this study, Japan is ranked 9th for government online service in the Global Innovation Index, 2019 (https://www.globalinnovationindex.org/).

\section{E. Civic Tech (A Portmanteau: Civic and Technology)}

The term 'Civic Tech' is a buzzword that encompasses technology to improve social good. As one of the definitions, the following set of statements was proposed [15].

- Technologies that are deployed to enhance the relationship between people and government.

- Technology projects involving intentional collaboration

between technologists, bureaucrats, entrepreneurs and nonprofit employees to engage the public or solve civic problems.

- The bridge between the government's mission and modern technology's potential.

As a more strategic view, Dietrich (2015) categorised Civic Tech into the following three pillars [16].

- Transparency \& accountability: holding governments to account by making information and processes transparent

- Citizen-government interaction: making the interaction of citizens with governments easier and more meaningful

- Digital tools for making citizens' everyday lives easier.

TABLE I: MIL LEVEL 4 COMPETENCY ITEMS AND TwO CASES

Socialised Creation [12] A Case of UGC A Case of Civic

[12]

Tech

\section{Socialized creation}

Media-information-literate socialized creators are able to create/produce and release information or media content with attractive qualities in society in an innovative and creative manner.

Collaborative creativity Media-information-literate socialized creators can collaborate with information, media content, and knowledge with diverse creators under heterarchical and fluid connections, contribute to the growth of the community, and have social, professional and ethical responsibility.

\section{Critical eye}

Media-information-literate socialized creators engage in communication and have a critical stance towards potential collaborators and the creator's own work to contribute effective collaborative creation through various means in an effective and efficient manner, as well as make impartial agreements with other creators.

\section{Building affordance}

Media-information-literate social creators understand and propose trends in terms of information, media content, knowledge production, and use, and they understand how media and information products introduce benefit to industries or public sectors.
Piapro Character

License,

Vocaloid

software

UGC, Produsage, Nico Douga, SoE, Mixer of individual properties, Derivative creation (participatory theatre), Doujin MMD, Goodwill

COVID-19 website, Civic Tech, communication in social media (e.g., Twitter), GitHub Gist, Agile, Hackathon, Goodwill
Play counts, comments, mylist

$\begin{array}{ll}\text { Karent, various } & \text { Open source, } \\ \text { merchandise, } & \text { GovTech, } \\ \text { sustainable } & \text { derivative websites, } \\ \text { project } & \text { VS COVID-19 } \\ & \text { websites }\end{array}$
GitHub repository, Data download service, Google analytics
News, Mass communication, Review of open

(Notice) 4. Building affordance is modified in part to adapt both industries and public sectors as introduction targets. 
Both explanations of Civic Tech asserted the cardinal importance of close collaboration among government, heterarchical individuals and IT engineers. Regarding this collaboration, Andrew Rasiej, a founder of New York's Civic Hall, emphasised the scaling of civic engagement.

... is to bring together diverse people from diverse sectors - government, not-for-profit, technology, media people, activists, corporates - and connect them with each other in an atmosphere that encourages collaboration [17].

Usually, Civic Tech organizations offer activities to receive small grants and operational support from the government. Also, Civic Tech encompasses a range of projects with government open data that act in the public good [18].

\section{F. Combining Civic Tech and GovTech}

There are subtle differences between Civic Tech and GovTech. Ransbeeck summarised the intrinsic difference as follows (Table II) [11]. While there are overt differences in stakeholders, the online information of both services has an overlapped target of citizens.

\begin{tabular}{cc} 
TABLE II: DIFFERENCE BETWEEN CIVIC TECH AND GOVTECH \\
\hline Civic Tech & GovTech \\
\hline Citizens as beneficiary & Government as customer \\
Community-centric & Operation-centric \\
Engagement & Efficiency \\
\hline
\end{tabular}

Ransbeeck summarised that Civic Tech and GovTech should not be seen as opposing tools and work best when used together. Civic Tech gets citizens involved in decision-making, and GovTech helps governments respond more efficiently to this input.

In this study, we sought to depict another concrete example of social capital to explain socialised creation competency through the investigation of the above-mentioned arena. Social contribution through collaboration by diverse individuals from different backgrounds is the noticeable trend where the competency of the advanced MIL emerges. Education for today's university students or citizens who have familiarity with and a presence on social media to improve society through their possible engagement and understanding of civil society is expected.

\section{A CASE}

\section{A. Civic Tech during Emergency Management}

In 2020, COVID-19 (coronavirus infectious disease) became an emergency that created a threat to people's lives. The situation posed an immediate risk to human health. In response, the Tokyo city government office opened a COVID-19 information website on 4 March (https://stopcovid19.metro.tokyo.lg.jp/en) (Fig. 2).

Regarding the production of this website service, Civic Tech, 'Code for Japan' (hereinafter CfJ), which is an entrusted corporation of individual IT engineers, received an order from Tokyo city and developed initial source code for the website on 1 March [19]. Meanwhile, the CfJ proposed a standard specification for survey data format and had an agreement between the cabinet secretariat, Ministry of internal affairs and communication and Ministry of economy, trade and industry.

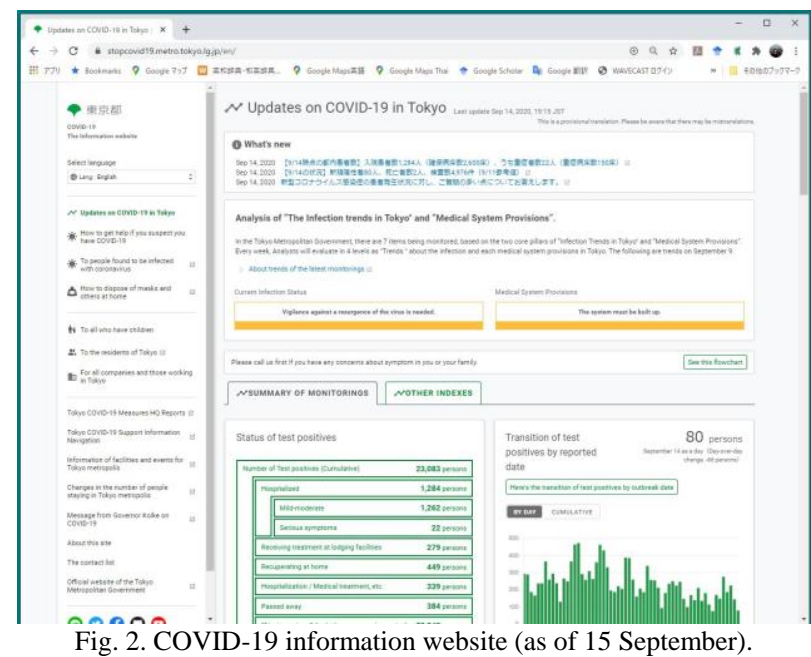

In addition, these public sections asked corporates to have collection and provision of data as their voluntary work.

The message communication regarding improvement of the website has emerged among public, corporate, civil activists, IT engineers and citizens on Twitter. Twitter was used as a forum to propose commentary, providing information about a real-world, instantaneous assessment of the interest, validity and stickiness of new ideas. It was a place to encourage and sum up a start-up idea. Twitter was also used by citizens to keep up to date with disaster information during COVID-19 and as an important curator of relevant countermeasures, thereby saving time and allowing for the crowdsourcing of information reviews. Twitter expanded the audience, allowing participants who may not otherwise have had a voice in the public services to provide their perspectives on disaster-related issues traditionally unrepresented in governmental information. Their message exchanges with a related hashtag reached 2,733 tweets by 2,499 users during 1-6 March. This community involved remarkable individuals including the governor of Tokyo, the CEOs of ICT companies, IT engineers, socialites, academics, congress members, politicians and citizens. In particular, IT Minister Audrey Tang in Taiwan was involved, and he also contributed to modifying the website's source code.

A record of Twitter communication was introduced to the social group graph analysis using the Clauset-Newman-Moore cluster analysis algorithm [20]; 23 subgroups were detected (Fig. 3). In the social group graph, three subgroups are subgroups of IT engineers. In the Twitter community, an initiator from $\mathrm{CfJ}$ to produce the website was a member of the IT engineers' subgroup, and the vice-governor of Tokyo, who used to work for Yahoo Japan, was the centre of the overall community. In addition, the active engagement of various individuals took place. Twitter served as a critical venue for engagement between the Tokyo city government and heterarchical individuals, and it was a successful, concrete case of cooperation between Civic Tech 
and GovTech.

Continuously, this cooperation has expanded. Ministry of internal affairs and communication, Ministry of economy, trade and industry and the CfJ have released another related information website to support citizens and small enterprises, 'VS COVID-19' (https://vscovid19.code4japan.org/), on 9 March. To develop source code, many Civic Techs, such as Code for Sabae, have contributed [21].

\section{DISCUSSION}

In the observed case, the code hosting service GitHub was used to develop source code for the website. It provides an open development environment and visibility of project activity through both notifications and a simple interface [22].

\section{A. Collaborative Creation}

The functions of GitHub assist in collaborative production and enabled the integration of products of distributed IT engineers. Additionally, Figma (https://www.figma.com/) of the collaborative interface design tool was used.

After the release of the website, many individual IT engineers commented to contribute to this activity. Many pull-requests to modify code and proposing issues were declared [23]. To organize collaboration, the CfJ proposed the following action principle on 3 March [24] (translated by the author).

\footnotetext{
Why we are here

To protect the life and health of citizens in Tokyo.

To disclose accurate data to people insideloutside the county.

To show the concrete effects of producing a proper product by a proper method through a collaborative process.

Action principles to develop a website User perspective

The meaning of information arises when it reaches people.

Recognize the importance of user experiences.

Through the collection of access, terms used in retrievals, and SNS data, engage numerical analysis. and find measures to use numerical analysis results.
}

This measure for recognition was appraised to be indispensable to gaining trust and involving the immediate action of IT engineers to participate in the project [19].

\section{B. Open Source}

In the COVID-19 information website coding activity, open source was used. Also, the CfJ asked individual IT engineers to approve their products as open source (MIT licence) because CfJ did not want to have stagnation resulting from a request for the intellectual property of contributors.

Regarding the use of open source for production, the following potential benefits are reported [25].

- Open-source is widely used in business.

- Open-source is the default when choosing software.

- The security of open-source software is usually better than that of proprietary software.

- Open-source has stability, rich user experiences and compatibility.
- In many firms, intellectual property policy on non-work open-source contributions is permitted.

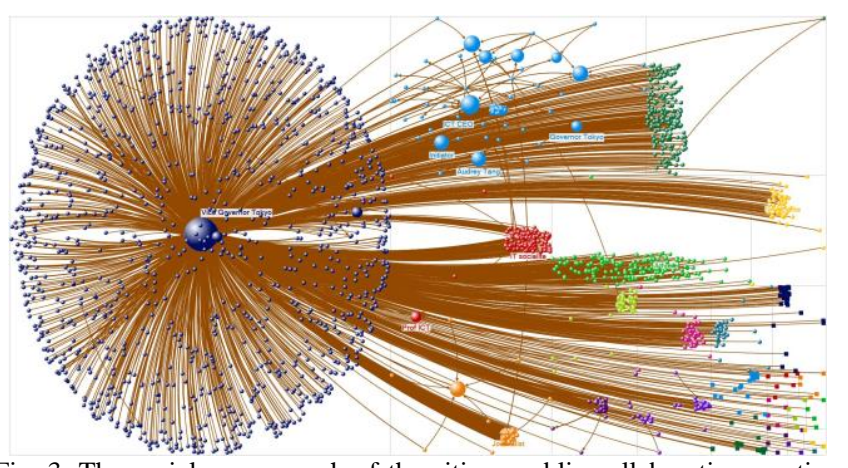

Fig. 3. The social group graph of the citizen-public collaborative creation network that has jointly produced information about the website, COVID-19. Node size represents the number of in-degree to use logarithmic mapping and colour represents subgroups. Nodes were positioned using the Harel-Koren Fast Multiscale algorithm [26].

Simultaneously, the Tokyo city government responded to open the source code on 6 March [27]. Information presented on the website was also offered as a creative commons licence. Thereinafter, the source code was used to develop derivative information websites in 64 areas in Japan as of 20 April [28].

\section{Short-Term and Short-Range Activities}

In our case, hackathons organised by heterarchical IT engineers have emerged. The first hackathon appeared on 7 March, and later hackathons were often built for improvement of the website.

A hackathon is a portmanteau made from 'hack' and 'marathon' and is a time-limited structured event to develop a service, system or application by diverse individuals. Recently, a hackathon organised by interested citizens who met in a collaborative environment to apply government open data in developing software applications has grown in popularity [29]. The United Nations Educational, Scientific and Cultural Organization (UNESCO) also promotes a hackathon to cultivate current information and communication to present opportunities for sustainable development [30]. In addition, activities that public sectors encourage is now embodied and includes the use of open data via the hosting or sponsoring of hackathons [31].

\section{CONCLUSION}

Our case study crosses a variety of diverse domains of information, knowledge, creative works and civic use. The observations demonstrated the substantial potential for the needs of advanced MIL competency to understand civil society and collaborative creation by public sectors and citizens. Robinson and Johnson reported the effects of a civic hackathon in which the weak engagement of citizens who participated by simply voting and signing petitions was a gateway to broader civic engagement [29]. This means interrelated activities among the public, citizens and creators. Socialized creation competencies stand in this arena (Fig. 4 shows the overall arena), and even users who access the website should understand this collaborative structure Citizens must take responsibility for their communities. 
Instead of further disillusionment with politics, digital tools can foster new entry points for civic engagement [32].

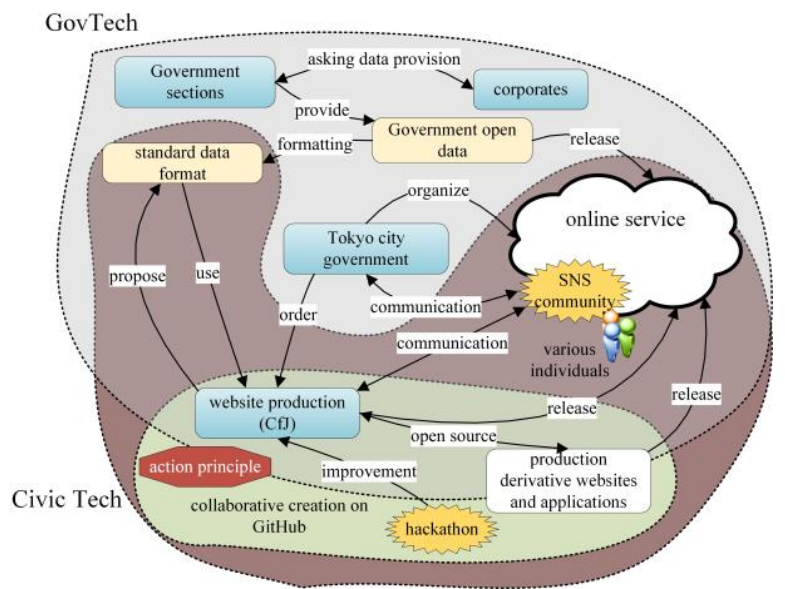

Fig. 4. Collaborative creation of the website.

Information in the case reveals more importance in the evolution of social capital by collaboration than content on the website. Fig. 5 shows the framework of an arena with a triad of elements of social capital. While our previous study showed SoE and UGC in the centre, the website and Civic Tech are located in the centre of this case.

The relation between factors seen in this case and socialised creation competencies are summarised in the right column of Table I.

While Civic Tech was used in the coding process, it is inclusive, user-centred, agile and open to different types of collaboration [33]. The process includes an iterative and agile method with a possibility of returning to and adjusting any stage after evaluation.

A similar reciprocal process of activities is seen in pedagogical lesson design. 'Double-loop learning theory' uses information feedback from activities and makes reconsideration of mental model and change decision-making rules of an individual [34]. The importance of this adjustment process was accepted and frequently seen in continuous theory, such as 'Laan theory,' which explains students' learning and connects students with other users in online [35] and 'design thinking,' in which a team redefines problems and creates innovative solutions to prototype and test [36].

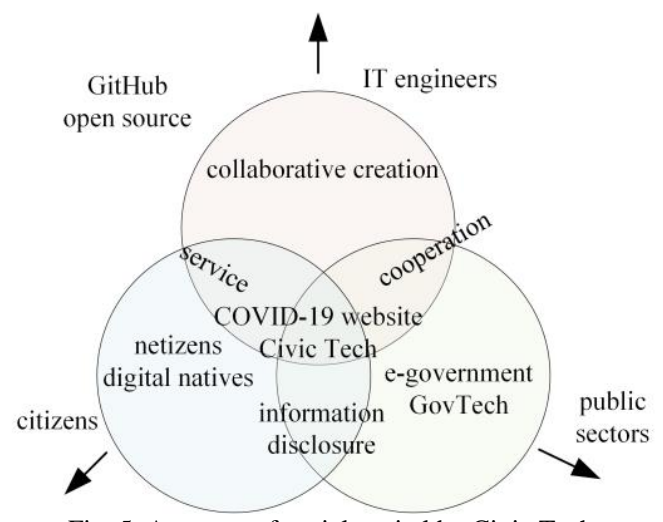

Fig. 5. An arena of social capital by Civic Tech.

In the education field, 'collaborative creation' is the idea of 'collective intelligence.' The collective effort is often greater than the sum of the individual contributions that compose it [37].

On the other hand, the importance of the special challenges are reported when teaching unfolding narratives of current events, but when students get the opportunity to engage with news in ways that are meaningful to them, learning comes alive [38]. Also, talented teachers are discovering ways to use digital media and technology to support civic engagement, "helping students to turn their self-expression into a form of public participation." The case we presented and socialised creation competency show a concrete example to connect with these educational principles as well.

\section{CONFLICT OF INTEREST}

The authors declare no conflict of interest.

\section{AUTHOR CONTRIBUTIONS}

Yoshida presented collected data, reviewed, contributed to the implementation of the investigation, and wrote the manuscript. Theeraroungchaisri gave overall academic advices from the view of education and communication technology.

\section{ACKNOWLEDGEMENT}

This work was supported by JSPS KAKENHI, Grant-in-Aid for Challenging Research (Pioneering), Grant Number 20K20512.

\section{REFERENCES}

[1] A. Smith, "Civic engagement in the digital age," Washington, DC: Pew Research Center, 2013.

[2] J. Uldam and A. Kaun, "Theorizing civic engagement and social media," in Social Media Materialities and Protest: Critical Reflections, Thomas Poell, Ed., London: Routledge, 2018.

[3] J. Chen, "Can online social networks foster young adults' civic engagement?" Telematics and Informatics, vol. 34, no. 5, pp. 487-497, 2017.

[4] W. L. Bennett, "Changing citizenship in the digital age," in Civic Life Online: Learning How Digital Media can Engage Youth, W. L. Bennett, Ed., MA: The MIT Press, 2008.

[5] A. Grizzle, "MIL, intercultural dialogue and global citizenship " in MILID Yearbook. Global Citizenship in a Digital World, S. H. Culver and P. Kerr, Eds., Bohus, Sweden: Nordicom, 2014, pp. 17-26.

[6] C. Wilson, A. Grizzle, R. Tuazon, K. Akyempong, and C. K. Cheung, Media and Information Literacy Curriculum for Teachers, Paris: UNESCO, 2011.

[7] UNESCO Communication and Information Sector, Glabal Media and Information Literacy Assessment Framework. Country Readiness and Competencies, Paris: UNESCO, 2013.

[8] T. Röhlinger, "The MILID dividend: A conceptual framework for MILID in the glocal society," in Media and Information Literacy for the Sustainable Development Goals, J. Singh, A. Grizzle, S. J. Yee, and S. H. Culver, Eds., Sweden: International Clearinghouse on Children, Youth and Media, NORDICOM University of Gothenburg, 2015, pp. 39-48.

[9] M. Yoshida and J. Iijima, "Media information literacy to produce collaborative social capital," Intemational Joumal of Information and Education Technology, vol. 9, no. 12, pp. 868-873, 2019.

[10] H. R. Gilman, "Civic tech for urban collaborative governance," Ps-Political Science \& Politics, vol. 50, no. 3, pp. 744-750, Jul 2017.

[11] W. V. Ransbeeck. (2020). What's the Difference between Civic Tech and GovTech. [Online]. Available: https://digileaders.com/whats-the-difference-between-civic-tech-and-g ovtech/

[12] L. Amin, "How open is the UK government? UK open governance scorecard results," London: Transparency International UK, 2015.

[13] M. M. Brown, "Understanding e-government benefits: An examination of leading-edge local governments," The American Review of Public Administration, vol. 37, no. 2, pp. 178-197, 2007. 
[14] Open Government Partnership. (2020). Open Government Declaration, [Online]. Available: https://www.opengovpartnership.org/process/joining-ogp/open-gover nment-declaration/

[15] G. O'Hara. (2018). WTF Is Civic Tech and Why Are We Here. [Online]. Available:

https://blog.codeforaustralia.org/wtf-is-civic-tech-and-why-are-we-her e-eef816c6e0

[16] D. Dietrich, "The role of civic tech communities in PSI reuse and open data policies," European Public Sector Information Platform Topic Report, No.2015/05, 2015.

[17] S. Zukin, The Innovation Complex: Cities, Tech, and the New Economy, New York: Oxford University Press, 2020.

[18] E. Gordon and P. Mihailidis, Civic Media: Technology, Design, Practice, MA: MIT Press, 2016.

[19] M. Takasu. (2020). The new corona virus countermeasure website of Tokyo city was developed by open source. [Online]. Available: https://business.nikkei.com/atcl/seminar/19/00058/031000042/

[20] A. Clauset, M. E. Newman, and C. Moore, "Finding community structure in very large networks," Physical Review E, vol. 70, no. 6, p. 066111, 2004.

[21] T. Fukuno. (2020). One day one production by Taisuke Fukuno. [Online]. Available: https://fukuno.jig.jp/codefor?off=20\&id=codefor

[22] E. Kalliamvakou, D. Damian, K. Blincoe, L. Singer, and D. M. German, "Open source-style collaborative development practices in commercial projects using GitHub," in Proc. 2015 IEEE/ACM 37th IEEE International Conference on Software Engineering, 2015, pp. 574-585.

[23] K. Kano. (2020). Why a website of measures for new corona disease of Tokyo was developed by NuxtJS. Best practice of Civic Tech. [Online] Available:

https://employment.en-japan.com/engineerhub/entry/2020/05/19/1030 00

[24] M. Takasu. (2020). Official website for COVID-19 prevalence measures was developed by open source. [Online]. Available: https://business.nikkei.com/atcl/seminar/19/00058/031000042/?P=2

[25] GitHub. (2020). Open source survey. [Online]. Available: https://opensourcesurvey.org/2017/\#about

[26] D. Harel and Y. Koren, "A fast multi-scale method for drawing large graphs," Journal of Graph Algorithms and Applications, vol. 6, no. 3 , pp. 179-202, 2002.

[27] M. Tokuriki. (2020). The ideal form of open data information disclosure learned from the corona countermeasure site in Tokyo. [Online].
Available: https://news.yahoo.co.jp/byline/tokurikimotohiko/20200312-0016727 $8 /$

[28]@yuto16. (2020). List of COVID-19 information websites in 49 prefectures. [Online]. Available: https://qiita.com/yuto16/items/602c7c3835a80895358e

[29] P. J. Robinson and P. A. Johnson, "Civic hackathons: New terrain for local government-citizen interaction?" Urban Planning, vol. 1, no. 2 , pp. $65-74,2016$.

[30] UNESCO. (2020). UNESCO supports the launch of the global media and information literacy youth hackathon. [Online]. Available: https://en.unesco.org/news/unesco-supports-launch-global-media-andinformation-literacy-youth-hackathon

[31] P. Johnson and P. Robinson, "Civic hackathons: Innovation, procurement, or civic engagement?" Review of Policy Research, vol. 31, no. 4, pp. 349-357, 2014.

[32] H. R. Gilman, Participatory Budgeting and Civic Tech: The Revival of Citizen Engagement, Washington, DC: Georgetown University Press, 2016.
[33] A. Knutas, V. Palacin, G. Maccani, and M. Helfert, "Software engineering in Civic Tech a case study about code for Ireland," in Proc. 2019 IEEE/ACM 41st International Conference on Software Engineering: Software Engineering in Society (ICSE-SEIS), 2019, pp. 41-50.

[34] C. Argyris, Increasing Leadership Effectiveness, New York: John Wiley \& Sons Inc, 1976.

[35] M. A. Chatti. (2013). The LaaN Theory. [Online]. Available: http://mohamedaminechatti.blogspot.com/2013/01/the-laan-theory.ht $\mathrm{ml}$

[36] M. Mintrom and J. Luetjens, "Design thinking in policymaking processes: Opportunities and challenges," Australian Journal of Public Administration, vol. 75, no. 3, pp. 391-402, 2016

[37] R. H. Jones and C. A. Hafner, Understanding Digital Literacies: A Practical Introduction, New York: Routledge, 2012.

[38] R. Hobbs, Digital and Media Literacy: Connecting Culture and Classroom, CA: Corwin Press, 2011.

Copyright (C) 2021 by the authors. This is an open access article distributed under the Creative Commons Attribution License which permits unrestricted use, distribution, and reproduction in any medium, provided the original work is properly cited (CC BY 4.0).

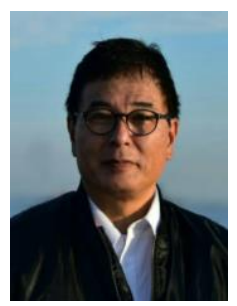

Masami Yoshida is working as a professor and his major field is educational technology and education for international understanding. He used to work for the National Institute of Multimedia Education (NIME) and was involved in projects to study faculty development and distance education. $\mathrm{He}$ also contributed to Japan International Cooperation Agencies (JICA) as a training expert in Thailand, Malaysia, and Papua New Guinea. Recently, he gave instruction to directors of educational TV in African, South American, and Asian countries at the JICA Okinawa training centre. Now, he teaches in the Faculty of Education (B.Ed. course), Graduate School of Education (M.Ed course), and Graduate School of Humanities and Studies on Public Affairs (Ph.D. course), Chiba University. His recent publication is "Education and social media," in the new latest of education. Cp. 15, The Centre for Research and Development in Teacher Education (ed.), Tokyo: Hukumura Pub., 2020 Prof. Yoshida is also a member of the Japan Society for Educational Technology and the Japan Association for College and University Education.

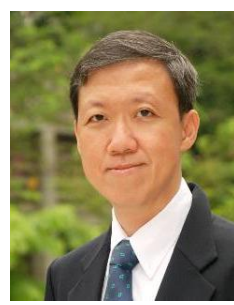

Anuchai Theeraroungchaisri obtained his bachelor's degree in pharmaceutical sciences and further his master's degree in computer sciences and $\mathrm{Ph} . \mathrm{D}$. in educational and communication technology from Chulalongkorn University. In the role of vice dean for educational innovation, he deployed moodle, an open-source learning management system, to become the faculty-wide virtual learning environment. Incorporate Google Apps for Education, Clicker (personal response system), Microsoft Office cloud as well as the tele-education between Thai-US graduate study and graduate seminar course in Social and Administrative Pharmacy graduate program, Faculty of Pharmaceutical Sciences, Chulalongkorn University. He also has deputy director position in Thailand Cyber University Project, Ministry of Higher Education, Science, Research and Innovation, in which He involved in many projects includes Thai MOOCs, TCU-Globe (Interoperability among the learning object repository network, enable search through at single query), e-Learning Professional development training program (the first fully online training certificate program in Thailand). 